\title{
Spinal cord stimulation in 60 cases of intractable pain
}

\author{
B A Simpson
}

\begin{abstract}
Sixty patients with spinal cord stimulators implanted for intractable pain lasting up to 50 years were followed for up to nine years. Forty seven per cent derived significant benefit, $23 \%$ modest benefit, $20 \%$ experienced no effect and $6.7 \%$ were made worse. Two were made worse after initial benefit. Complications, indications and factors relevant to the mode of action are discussed.
\end{abstract}

The analgesic effect of electrical stimulation has been known since Roman times, when the shock from an electric fish was used to relieve gout pain. ${ }^{12}$ The gate theory of pain ${ }^{3}$ inspired Shealy to implant the first dorsal column stimulator in a human in $1967,{ }^{4}$ the dorsal columns being rich in the large, low-threshold A- $\beta$ fibres, which were alleged to "close the gate" against nociception-subserving afferents.

Several thousand electrical spinal cord stimulators have since been implanted but the procedure remains controversial owing to a lack of agreement regarding its indications, lack of consistency in reported efficacy and lack of understanding of its mechanism of action.

\section{Materials and methods}

Of the first 62 consecutive cases with spinal cord stimulators inserted by the Department of Neurosurgery at The London Hospital, 60 were examined retrospectively. Data from two cases could not be retrieved and these were excluded from the report. The 60 cases comprised 34 males, age range 28-74 (median 55) years, duration of symptoms one to 37 (median seven) years and 26 female, ages 2174 (57) years and duration of symptoms three months to 50 (eight) years. Follow up was from two weeks to nine years (median 29 months); 19 were followed for more than five years. All electrodes were inserted via laminectomy and in most cases secured to the dura with silk sutures. There were five unipolar electrodes, 11 bipolar of percutaneous type (but not implanted percutaneously), 32 bipolar plate, 11 4-pole plate electrodes and one unrecorded.

Of 24 who were tested via temporary external leads only four failed to proceed to full implantation. Those four cases are included in the analysis. No temporary external leads were employed after January 1983 and implantation at a single operation was first performed in April 1979. Overall, four of the 56 "permanently" implanted had an intracorporeal pulse generator and 52 had radiofrequency (RF) coupled devices with an external transmitter. Electrode positions were: high cervical 18 cases, mid cervical three, low cervical four, high thoracic 18 , mid thoracic 15 and low thoracic two cases. In cases with facial pain the electrodes were placed over the spinal trigeminal nucleus and tract.

The systems were inserted for a variety of pain states unresponsive to all other measures tried. From July 1982, 48 of the 56 permanently implanted patients $(86 \%)$ were followed up in a dedicated neurostimulation clinic held weekly. Detailed records were kept of wave forms and fields recorded via surface electrodes. Faults in internal and external apparatus were diagnosed and located and appropriate remedial measures taken. ${ }^{5}$

Outcome was assessed according to four categories:

1) Made worse (MW): self-explanatory.

2) No effect (NE): on symptoms in the presence of a functioning stimulator.

3) Modest benefit (MB): definite improvement gained, but without substantial benefit, for example short-lived relief, no significant change in medication, activity, sleep pattern etc.

4) Significant benefit (SB): complete relief or partial, but sustained relief with a significant effect on medication, activity, life-style, sleep pattern. Consistent praise of the apparatus by the patient, being awoken in pain when accidently disconnected during sleep, significant deterioration coinciding with apparatus failure.

The data are too few to subject them to statistical analysis.

\section{Results}

Four patients $(6 \cdot 7 \%)$ were made worse. All were male but there were no other common features. Another two were made worse after initial benefit; one had developed an aversion to the implanted device after several months of $\mathrm{MB}$ and the other change occurred after three years and six months of SB in a man with facial anaesthesia dolorosa who developed primary hyperparathyroidism. Twelve patients $(20 \%)$ reported no effect on their pain; there were no common features. Modest benefit was gained by $14(23.3 \%)$ and significant benefit by $28(46 \cdot 7 \%)$. Thus $70 \%$ derived benefit. Overall, 10 patients experienced complete relief of their pain, three had virtually complete relief and three who had 
Table 1 Efficacy: sex distribution

\begin{tabular}{llllllll}
\hline & Total & $M W$ & $N E$ & $M B$ & $S B$ & $M B \rightarrow M W$ & $S B \rightarrow M W$ \\
\hline Male & 34 & 4 & 3 & 11 & 15 & - & 1 \\
Female & 26 & - & 9 & 3 & 13 & 1 & - \\
\hline
\end{tabular}

Table 2 Results related to age at first operation

\begin{tabular}{|c|c|c|c|c|c|c|c|}
\hline Age & Total & $M W$ & $N E$ & $M B$ & $S B$ & $M B \rightarrow M W$ & $S B \rightarrow M W$ \\
\hline-29 years & 3 & - & - & - & 3 & - & - \\
\hline $30-39$ years & 6 & - & 1 & 2 & 3 & - & - \\
\hline $40-49$ years & 12 & 1 & 4 & 2 & 5 & - & - \\
\hline $50-59$ years & 13 & 1 & 1 & 5 & 5 & - & 1 \\
\hline $60-69$ years & 19 & 2 & 4 & 3 & 9 & 1 & - \\
\hline $70+$ years & $\begin{array}{r}7 \\
60\end{array}$ & $\overline{4}$ & $\begin{array}{r}2 \\
12\end{array}$ & $\begin{array}{r}2 \\
14\end{array}$ & $\begin{array}{r}3 \\
28\end{array}$ & $\overline{1}$ & $\overline{1}$ \\
\hline
\end{tabular}

Table 3 Results related to duration of symptoms

\begin{tabular}{|c|c|c|c|c|c|c|c|}
\hline Duration & Total & $M W$ & $N E$ & $M B$ & $S B$ & $M B \rightarrow M W$ & $S B \rightarrow M W$ \\
\hline$<1$ year & 1 & - & 1 & - & - & - & - \\
\hline $1-4$ years & 20 & 2 & 5 & 3 & 9 & 1 & - \\
\hline 5-9 years & 19 & - & 3 & 5 & 10 & - & 1 \\
\hline $10-14$ years & 7 & - & 2 & 4 & 1 & - & - \\
\hline $15-19$ years & 4 & 2 & - & 1 & 1 & - & - \\
\hline $20-24$ years & 4 & - & 1 & - & 3 & - & - \\
\hline $25-30$ years & 1 & - & - & 1 & - & - & - \\
\hline \multirow[t]{2}{*}{$>30$ years } & 5 & - & - & 1 & 4 & - & - \\
\hline & $\star 61$ & 4 & 12 & $\star 15$ & 28 & 1 & 1 \\
\hline
\end{tabular}

ॠOne patient had two pains of different duration

Table 4 Results related to presence or absence of appropriate evoked paraesthesiae

\begin{tabular}{llllllll}
\hline & Total & $M W$ & $N E$ & $M B$ & $S B$ & $M B \rightarrow M W$ & $S B \rightarrow M W$ \\
\hline Appropriate & & & & & & & \\
$\quad$ paraesthesiae & & & & & & & \\
Present & 45 & 3 & 5 & 8 & 27 & 1 & 1 \\
Absent & 9 & - & 4 & 4 & 1 & - & - \\
Unknown & 6 & 1 & 3 & 2 & - & - & - \\
\hline
\end{tabular}

more than one pain obtained complete relief of one. Of the 20 implanted after a period of testing via external leads, one became $M W$, two NE, five MB and 12 SB.

Women were more likely to feel that there was no effect than were men, but if a woman felt an effect it was more likely to be significant (table 1). The proportion benefiting became smaller with increasing age; eight of the nine cases below 40 years benefited. However, more than half of those over 60 years derived benefit (table 2). One third had had intractable pain for more than 10 years, but long duration did not mitigate against success; seven of the 10 with pain duration of more than 20 years derived significant benefit (table 3 ).

Stimulation via electrodes placed over the dorsal columns evokes sensations of tingling, "bumping" or warmth. In table 4 "appropriate paraesthesiae" refers to such sensations occurring within the painful area. The four $\mathrm{MB}$ and one SB without appropriate paraesthesiae had evoked sensations, but not in the painful area. It appears that an evoked sensation is necessary for pain relief, but it does not have to be in the painful area although in the majority of cases it was. Evoked paraesthesiae do not, however, guarantee pain relief (table 4).

It can be seen from table 5 that the conditions most likely to respond are traumatic and unplanned surgical peripheral denervations, idiopathic chronic focal pain, ischaemic pain, painful paraparesis, paraplegia and hemiparesis, particularly if caused by an acute event, and the "failed back" syndrome (chronic low back pain usually with sciatica after several or many surgical procedures). Success may occur, but with less certainty, in the thalamic syndrome, phantom pain, stump pain, anaesthesia dolorosa and some nociceptive pains. The single patients each with syringomelia and tabes dorsalis also benefited. Post herpetic neuralgia yielded only one MB from three cases.

The three patients with complete paraplegia

Table 5 Results related to diagnosis

\begin{tabular}{|c|c|c|c|c|c|}
\hline & Total & $S B$ & $M B$ & $N E$ & $M W$ \\
\hline \multirow{2}{*}{$\begin{array}{l}\text { Traumatic and unplanned surgical peripheral denervation } \\
\text { Painful paraparesis, paraplegia and hemiparesis }\end{array}$} & 6 & 5 & - & 1 & - \\
\hline & 2 & 2 & - & - & - \\
\hline - chronic disease & 5 & 2 & 1 & 1 & 1 \\
\hline - CVA & 1 & 1 & $\bar{z}$ & $\bar{z}$ & $=$ \\
\hline $\begin{array}{l}\text { Idiopatnic } \\
\text { Painful conus lesion (trauma) }\end{array}$ & 1 & 1 & $\overline{-}$ & 1 & $\bar{z}$ \\
\hline "Failed back" syndrome & 7 & 4 & 1 & 2 & - \\
\hline Phantom pain (leg) & 4 & 1 & 2 & 1 & - \\
\hline Stump pain一arm & 1 & 1 & $\overline{1}$ & $\overline{2}$ & $\bar{z}$ \\
\hline \#A - leg & 4 & 1 & 1 & 2 & $\overline{1}$ \\
\hline${ }^{\star}$ Anaesthesia dolorosa (face) & 3 & 1 & $\overline{3}$ & 1 & $\frac{1}{2}$ \\
\hline †Thalamic syndrome & 10 & 3 & $\underline{3}$ & 2 & 2 \\
\hline $\begin{array}{l}\text { Post thalamotomy pain } \\
\text { Ischemicleg }\end{array}$ & $\begin{array}{l}1 \\
2\end{array}$ & $\overline{2}$ & $\overline{-}$ & $\bar{z}$ & 1 \\
\hline $\begin{array}{l}\text { Ischaemic leg } \\
\text { arcinos }\end{array}$ & 2 & 2 & $\overline{1}$ & $\overline{1}$ & 二 \\
\hline Nociceptive (eg carcinoma, spondylosis) & 4 & 3 & 3 & 1 & $\bar{z}$ \\
\hline Idiopathic chronic focal pain (loin, groin etc) & 6 & $\underline{3}$ & 1 & 二 & 二 \\
\hline Syrinx & 1 & - & 1 & - & $\overline{-}$ \\
\hline $\begin{array}{l}\text { Tabes dorsalis } \\
\text { Post herpetic neuralgia }\end{array}$ & 3 & 二 & 1 & 2 & - \\
\hline
\end{tabular}

The total exceeds 60 as some had more than one pain, for example, stump and phantom, which are noted separately in this table. In the text the overall response per patient is given.

$\star$ One patient was made worse, but first enjoyed significant benefit for three years and six months and is therefore recorded as SB in the table.

tOne patient was made worse after initial modest benefit; the overriding result was $M W$. 
Table 6 Failure or complication leading to re-operation

\begin{tabular}{llllllll}
\hline & Electrode & $\begin{array}{l}\text { Leads } \\
\text { insulation }\end{array}$ & Connector & $\begin{array}{l}\text { Receiver- } \\
\text { transducer }\end{array}$ & Infection & CSF leak & Other \\
\hline Operations & 38 & 4 & 14 & 7 & 7 & 2 & 16 \\
Patients & 16 & 4 & 10 & 7 & 3 & 2 & 15 \\
\hline "“lut"
\end{tabular}

«"Lead" refers to the cable

comprised one SB, one NE and one MW, but four out of five with a partial cord lesion (four paraparetic and one hemiparetic) were SB with one MB.

Of effective frequencies selected, $81 \%$ were within the range 50-120 cycles per second. Only two patients found that only frequencies below this range were effective and only one patient found frequencies up to $1400 \mathrm{cps}$ effective.

Of effective pulse widths recorded, $19 \%$ were less than $0.5 \mathrm{~ms}$ and $67 \%$ were 0.5 to $0.8 \mathrm{~ms}$. The commonest effective pulse width employed was $0.5 \mathrm{~ms} \mathrm{(33 \% ).}$

Eleven of the patients who benefited used their stimulator for 24 hours every day, 14 used it all day and left it off at night and in 17 the pattern was different or unknown. Of six patients who developed tolerance to the analgesic effect, five were continuous users.

There were no deaths and no neurological deterioration related to surgery or to stimulation. The complications most frequently leading to re-operation were electrode failure (through electrode fracture or the interposition of scar tissue between electrode and dura), electrode movement and connector failure (table 6). Infection occurred in three cases $(5 \%)$ two of whom had had temporary external leads. Overall, the average total number of operations per patient was $2 \cdot 8$. If operations for infection and for the original implantation are excluded, however, then the average number of additional operations after implantation per non-responder (MW plus NE) was 0.56 and per responder (MB plus $\mathrm{SB}$ ) was 1.7 . Responders therefore had three times as many additional operations as non-responders. Almost $50 \%$ (29 cases) needed no re-operation after initial implantation.

\section{Discussion}

This series covers a wide range of conditions which differs from that in many other series. Mittal, for example, had a higher proportion (more than $60 \%$ ) of "failed back" syndrome ${ }^{6}$ and in the USA this figure reaches $94 \%{ }^{7}$ compared with $12 \%$ in the present series. Others have a greater experience of post amputation (stump and phantom) pain. ${ }^{89}$ Whilst the ability to evoke paraesthesiae was a necessary condition for pain relief, it was not necessary for the paraesthesiae to be within the painful area (although in most cases it was) and this conflicts with the findings of others. ${ }^{111}$

Spinal cord stimulation (SCS) is not a universal analgesic; it is most effective against pain due to partial and abrupt deafferentation, to ischaemia and in some nociceptive pains. Thus painful paraparesis responds better than complete paraplegia, particularly if caused by acute trauma. In one report the best results with SCS in cancer pain occurred in the cases which had neurological deficit. ${ }^{12}$ The effectiveness of SCS in ischaemic limb pain has been widely reported ${ }^{13-16}$ and is supported here. The results in phantom pain were similar to those of others. ${ }^{8917}$ The overall result of this series is consistent with other series. An overall success rate of $40-60 \%$ has been reported by several authors ${ }^{6-8} 10^{17-20}$ although others have reported less success. ${ }^{1121}$ Young reported that an initial $47 \%$ relief fell to only $8 \%$ after three years, ${ }^{22}$ whereas Long found that better case selection improved his success rate from $33-70 \% .^{23}$ Differences in patient populations and in methods of assessment make comparisons unreliable, however.

Implantation after a period of trial stimulation resulted in $17 / 20$ (85\%; four were not permanently implanted) deriving benefit compared with $25 / 36(69.4 \%)$ of those implanted directly. Trial stimulation, however, did not prevent one $\mathrm{MW}$ and two NE and the infection rate was higher after a percutaneous trial $(10 \%$ compared with $2 \cdot 8 \%$ ). Trial stimulation therefore appears to increase the rate of subsequent success but is not infallible and may increase morbidity.

Good results from SCS depend not only upon case selection, but also upon thorough follow up by a team able to recognise and to rectify faults and a willingness on the part of both patient and surgeon to re-operate when necessary. Those benefiting from SCS had three times as many additional operations as non-responders, which supports the assessment and suggests that good responders were more willing to undergo re-operation.

The results suggest that infected systems should be removed completely as attempts at preservation are unlikely to be successful.

Tolerance to SCS can be prevented by avoiding continuous use. Tolerance may have contributed to the loss of response with time reported by others. 224

Assessing the results of treatment of chronic pain is problematical. After months or years of relief or modulation, the quality and intensity of the original pain may not be accurately remembered. Patients' quantifications may be unreliable (for example, " $20 \%$ relief, but the pain is twice as bad when I stop stimulating"). Patients' interpretations may differ from the doctor's: a patient complained that his stimulator did not work because as soon as he switched it off the pain returned. Another reported no pain relief, but was able to discontinue her intake of approximately 200 analgesic tablets per month.

Koeze $^{25}$ assessed 26 patients who are included in the present series and who were extant and using stimulation in 1986. He found on a quantitative assessment that exactly half obtained $50 \%$ or more relief, but there were discrepancies between this and the patient's assessment of the "worth" of the treatment. However, assessments by three different third parties (clinician, psychologist and relative or close friend) correlated well with each other. Return to work is not regarded as a useful 
marker in the present series whose median age was in the mid fifties and which contained many disabled people.

Appropriate stimulation must be occurring before a case is designated as "failed stimulation"; some cases are in fact failed attempts at achieving appropriate stimulation.

The mechanism of action of SCS is unknown. Fully blind studies are impossible but an explanation in terms of placebo response is refuted by the success rate and by the longevity of response in addition to the need for the electrodes to be above the neurological level of the pain. A patient may experience evoked paraesthesiae but have no pain relief until the electrodes are re-positioned or the stimulation parameters are altered. Many other treatments will have been tried before SCS including, surgical procedures, drug therapy, physiotherapy, acupuncture, hypnotherapy, relaxation therapy and transcutaneous electrical nerve stimulation (TENS) without a placebo response occurring. Finally, SCS can induce analgesia in animals. ${ }^{26}$

Although elevated sensory thresholds ${ }^{1012} 27$ and reduced somatosensory evoked potentials $^{28-30}$ in the presence of SCS in humans have been reported, an overt alteration in sensation is not an accompaniment of effective SCS. ${ }^{28}$ Furthermore, SCS is no more effective against nociceptive pain than against deafferentation pain. SCS activates several pathways in the spinal cord ${ }^{31}$ and has been shown to influence thalamic activity in the monkey and the human. ${ }^{29} 3233$. In peripheral vascular disease the analgesic effect of SCS may be, in part, secondary to an increase in perfusion. ${ }^{13-16}$

Any theory must explain the evoked paraesthesiae felt in phantom limbs, the universal observation that the electrodes must be both ipsilateral and (except in facial pain) neurologically rostral to the painful area, the autonomic effects of SCS and the fact that the pain is converted into a neutral or even a pleasant sensation rather than being simply blocked or "gated".

SCS is reversible, non-destructive, has a low morbidity and unlike destructive measures does not itself produce deafferentation pain. Controversy persists regarding the method of implantation and the validity of selection by trial stimulation but SCS can be a highly effective therapy in selected chronically suffering patients for whom little or nothing else can be offered.

I am grateful to Professor E S Watkins and Mr F Afshar for their permission to report cases under their care. I acknowledge Dr TH Koeze's contribution to this work.

A shortened version of this paper was read at the meeting of the Society of British Neurological Surgeons, Glasgow, September 1988. ${ }^{34}$

1 Kellaway P. The part played by electric fish in the early history of bioelectricity and electrotherapy. Bull Hist Med 1946;20:112-37.
2 Kane K, Taub A. A history of local electrical analgesia. Pain 1975;1:125-38.

3 Melzack R, Wall PD. Pain mechanisms: a new theory. Science 1965;150:971-9.

4 Shealy CN, Mortimer JT, Reswick JB. Electrical Inhibition of Pain by Stimulation of the Dorsal Columns: Preliminary Clinical Report. Anesth Analg (Cleveland) 1967; inary Clinica

5 Koeze TH, Simpson BA, Watkins ES. Diagnosis and Repair of Malfunctions of Implanted Central Nervous System Stimulators. Appl Neurophysiol 1984;47:111-16.

6 Mittal B, Thomas DGT, Walton P, Calder I. Dorsal column stimulation (DCS) in chronic pain: report of 31 cases. Ann Roy Coll Surg Eng 1987;69:104-9.

7 Burton CV. Session on spinal cord stimulation. Safety and Clinical Efficacy. Neurosurgery 1977;1:214-15.

8 Krainick JU, Thoden U, Riechert T. Spinal Cord Stimulation in Post Amputation Pain. Surg Neurol 1975;4:167-70.

9 Miles J, Lipton S. Phantom limb pain treated by electrical stimulation. Pain 1978;5:373-82.

10 Nashold BS, Friedman H. Dorsal column stimulation for control of pain. Preliminary report on 30 patients. $J$ control of pain. Preliminar

11 Urban BJ, Nashold BS. Percutaneous epidural stimulation of the spinal cord for relief of pain. J Neurosurg 1978, 48:323-8.

12 Hoppenstein $R$. Electrical stimulation of the ventral and dorsal columns of the spinal cord for relief of chronic intractable pain: preliminary report. Surg Neurol 1975, 4:187-94.

13 Broseta J, Barbera J, de Vera JA, et al. Spinal cord stimulation in peripheral arterial disease. A co-operative study. $J$ Neurosurg 1986;64:71-80.

14 Jacobs MJHM, Jorning PJG, Joshi SR, Kitslaar PJEHM Slaaf DW, Reneman RS. Epidural Spinal Cord Electrical Stimulation Improves Microvascular Blood Flow in Severe Limb Ischaemia. Ann Surg. 1988;207:179-83.

15 Tallis RC, Illis LS, Sedgwick EM, Hardwidge C, Garfield JS. Spinal Cord Stimulation in Peripheral Vascular Disease. J Neurol Neurosurg Psychiat 1983;46:478-84.

16 Augustinsson LE. Epidural Spinal Electrical Stimulation in Peripheral Vascular Disease. Pace 1987;10:205-6.

17 Neilson KD, Adams JE, Hosobuchi Y. Phantom limb pain Treatment with dorsal column stimulation. $J$ Neurosurg 1975;42:301-7.

18 Neilson KD, Adams JE, Hosobuchi Y. Experience with dorsal column stimulation for relief of chronic intractable pain: 1968-73. Surg Neurol 1975;4:148-52.

19 Richardson RR, Siqueira EB, Cerullo LJ. Spinal Epidura Neurostimulation for Treatment of Acute and Chronic Intractable Pain: Initial and Long Term Results. Neurosurgery 1979;5:344-8.

20 Shealy CN. Dorsal Column Stimulation: Optimization of Application. Surg Neurol 1975;4:142-5.

21 Hunt WE, Goodman JH, Bingham WG. Stimulation of the Dorsal Spinal Cord for Treatment of Intractable Pain: A Preliminary Report. Surg Neurol 1975;4:153-6.

22 Young RF. Evaluation of Dorsal Column Stimulation in the Treatment of Chronic Pain. Neurosurgery 1978;3:373-9.

23 Long DM, Erickson D, Campbell J, North R. Electrical Stimulation of the Spinal Cord and Peripheral Nerves for Pain Control. A 10-Year Experience. Appl Neurophysiol 1981;44:207-17.

24 Illis LS, Read DJ, Sedgwick EM, Tallis RC. Spinal Cord Stimulation in the United Kingdom. $J$ Neurol Neurosurg Psychiat 1983;46:299-304.

25 Koeze TH, Williams AC deC, Reiman S. Spinal cord stimulation and the relief of chronic pain. J Neurol Neurosurg Psychiat 1987;50:1424-9.

26 Shealy CN, Mortimer JT, Hagfors NR. Dorsal Column Electroanalgesia. J Neurosurg 1970;32:560-4.

27 Lindblom U, Meyerson BA. Influence on touch, vibration and cutaneous pain of dorsal column stimulation in man. and cutaneous pain of
Pain 1975;1:257-70.

28 Friedman H, Nashold BS, Somjen G. Physiological effects of dorsal column stimulation. In: Bonica JJ, ed. Advances in neurology vol 4. International Symposium on Pain. New York: Raven Press 1974,769-73.

29 Larson SJ, Sances A, Riegel DH, Meyer GA, Dallman DE Swiontek T. Neurophysiological effects of dorsal column stimulation in man and monkey. J Neurosurg 1974;41: 217-223.

30 Blair RDG, Lee RG, Vanderlinden G. Dorsal Column Stimulation. Its Effect on the Somatosensory Evoked Response. Arch Neurol 1975;32:826-9.

31 Bantli H, Bloedel JR, Long DM, Thienprasit P. Distribution of activity in spinal pathways evoked by experimental tion of activity in spinal pathways evoked by experimental

32 Bantli $\mathbf{H}$, Bloedel JR, Thienprasit P. Supraspinal interactions resulting from experimental dorsal column stimulations resulting from experimental dor

33 Modesti LM, Waszak M. Firing Pattern of Cells in Human Thalamus during Dorsal Column Stimulation. App Neurophysiol 1975;38:251-8.

34 Simpson BA. Dorsal column stimulation for pain: a review of 60 cases. J Neurol Neurosurg Psychiat 1989;52:928. 